\title{
Trephine Craniotomy versus Burr Hole Drainage for Chronic Subdural Hematoma-An Institutional Analysis of 156 Patients
}

\author{
Ramesh Chandra Vemula $^{1} \quad$ B. C.M. Prasad ${ }^{1} \quad$ Venkat Koyalmantham $^{1} \quad$ Kunal Kumar $^{1}$ \\ ${ }^{1}$ Department of Neurosurgery, Sri Venkateswara Institute of \\ Medical Sciences (SVIMS), Tirupati, Andhra Pradesh, India \\ Address for correspondence Venkat Koyalmantham, MBBS, MCh, \\ Department of Neurosurgery, Sri Venkateswara Institute of \\ Medical Sciences (SVIMS), Tirupati, Andhra Pradesh 517507, India \\ (e-mail: dr.venkat2k3@gmail.com, daretoemail@gmail.com).
}

Indian J Neurotrauma:2020;17:110-120

\begin{abstract}
Introduction Some neurosurgeons believe that doing a trephine craniotomy (TC) decreases the chance of recurrence in chronic subdural hematoma (cSDH). But this is not supported by any evidence.

Methods A retrospective analysis of patients who were operated for cSDH from 2014 to 2019 at our institute was done. Factors causing recurrence were studied.

Results A total of 156 patients were operated in the given period, among which 88 underwent TC and 68 patients underwent burr hole drainage (BHD) for evacuation of $\mathrm{cSDH}$. All patients underwent two trephines or two burr holes placed according to the maximum thickness of the hematoma. Rate of recurrence in trephine group was $12.5 \%$ and in burr-hole group was $11.76 \%$ and was not statistically significant. Significant factors for recurrence included nontraumatic cSDH, anticoagulant use, presence of membranes, preoperative computed tomography (CT) showing iso- or mixed-density subdural collection and SDH volume $>60 \mathrm{~mL}$. There was selection bias for the procedure. Patients with subdural membranes were preferentially taken for TC as the percentage of subdural membrane found intraoperatively was significantly greater in trephine group (51.1\%) than burr-hole group (17.6\%) ( $p$ value $<0.001$ ).

When all the patients who showed membranes in CT scan were excluded, there was no statistical difference in the base line characteristics of both the groups. After excluding the patients with membranes in preoperative CT scan, there was no significant difference in recurrence rate between the two groups.

Keywords

- burr hole drainage

- chronic subdural

hematoma (SDH)

- recurrence

- risk factors

- trephine craniotomy

In TC group with membranes, 8 out of 45 had recurrence, whereas in burr-hole group with membranes, 8 out of 12 had recurrence. This difference was statistically significant. ( $p$ value $<0.001$ ).

Conclusion Surgical intervention in both modalities improves patient outcome with an overall recurrence rate of $12.17 \%$. In the absence of any identifiable membranes in preoperative CT scan, BHD is the preferred surgical intervention. We prefer TC as first choice for patients with membranes in CT scan.
\end{abstract}

\section{Introduction}

Chronic subdural hematoma (cSDH) is primarily a disease of elderly, possibly due to increasing brain atrophy and the correlated increased baseline stretch on the bridging veins which makes them more vulnerable to minor head trauma. ${ }^{1}$
The incidence of cSDH among the population aged 80 years or older has nearly tripled since $1990 .^{2}$

Various modes of surgical intervention are available for the management of symptomatic cSDH and there is considerable confusion regarding these in various studies. ${ }^{3-8}$ Large craniotomy, minicraniotomy, trephine craniotomy 
(TC [single or double]), burr hole drainage (BHD), twist drill craniostomy (TDC) (spontaneous hematoma efflux or catheter drainage), with or without subdural drain placement, small craniotomy, and endoscopic removal are a few procedures to name. At our institute, we do TDC only for very high-risk patients. For patients with acute SDH, craniotomy was a routine. For normal-risk cSDH patients, one of the two described procedures, $\mathrm{BDH}$ or TC was routinely performed.

\section{Aims and Objectives}

There is a difference in opinion among neurosurgeons, with a strong belief in some, that doing a TC decreases the chance of recurrence in cSDH compared with BHD. But there is little scientific evidence to support this popular notion. The aim of our study is as follows:

- To study the outcome of surgical intervention and associated complications.

- To know the recurrence rates for these two groups.

- To find out the various factors contributing to recurrence.

\section{Material and Methods}

A retrospective analysis of all CSDH patients operated in our institute between January 2014 and August 2019 was done. Patients who underwent either TC or BHD were included and divided into these two groups. The choice of either procedure was decided by individual surgeons' preference. Patients with acute SDH, those who underwent large craniotomy or TC were excluded from the study.

\section{Surgical Protocol}

Two burr holes were routinely placed in all patients, either under local anesthesia (LA) or general anesthesia (GA). For patients in TC group, two trephines were placed, either under LA or under GA. Dura was coagulated and opened in cruciate manner in all the patients in both groups and left open in all. Burr holes were not filled with bone dust and trephine bone flap was loosely replaced in all ( $\boldsymbol{- F i g . ~ 1 ) . ~ T h e ~ c e n t r a l ~ o p e n i n g ~}$ in trephine was made in all cases and subgaleal space was created in all patients in both groups. No drain was kept in any of the patients.
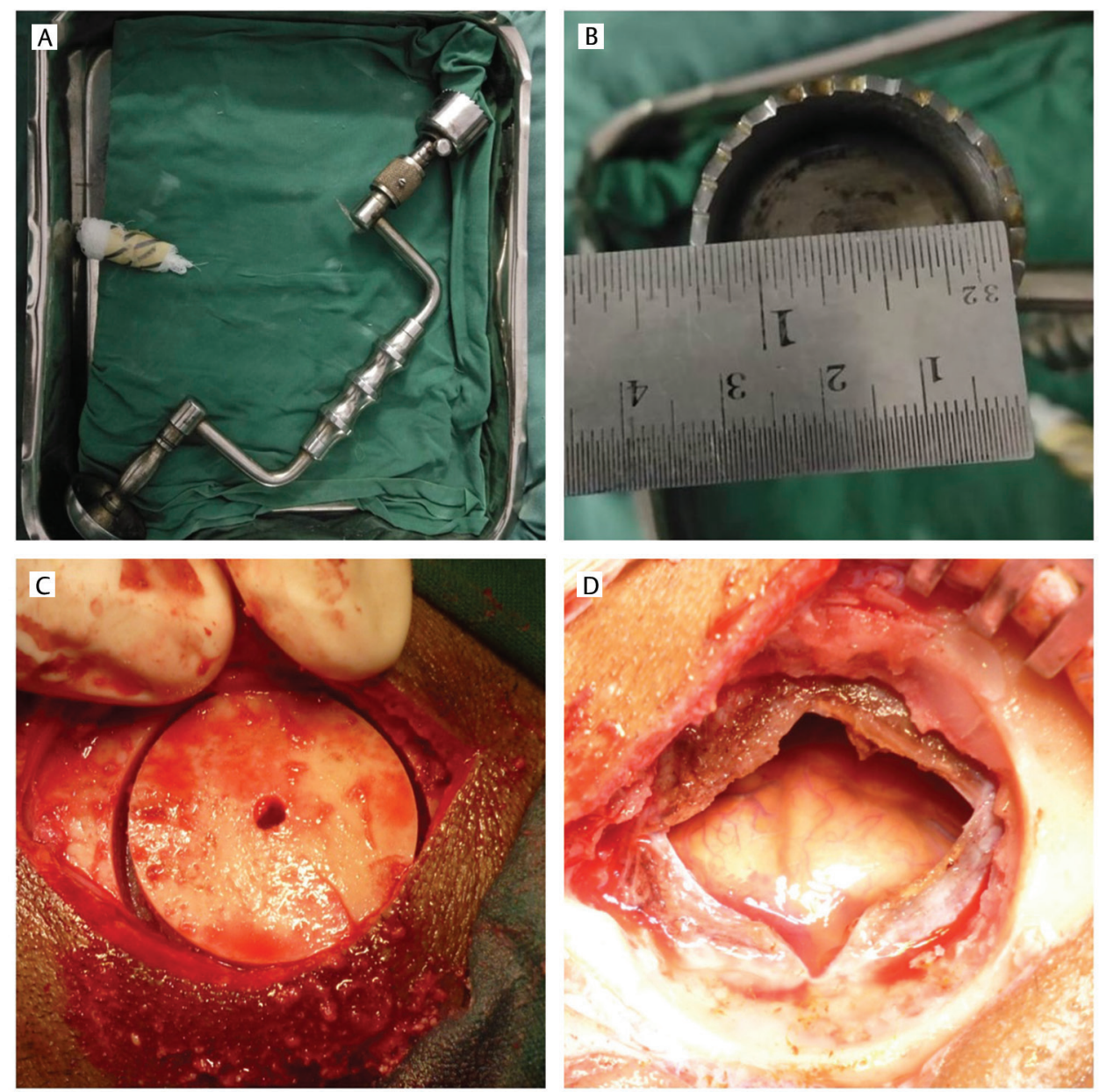

Fig. 1 (A) Trephine used for trephine craniotomy, (B) diameter of trephine is $3 \mathrm{~cm},(\mathbf{C})$ trephine bone flap, (D) after removal of membranes. 
The clinical features, radiology, surgical details, recurrence rate, and complications were analyzed. Outcome was measured using Glasgow Outcome Score (GOS). Data were obtained from medical and radiological records, follow-up records, clinical examination, and telephonic interviews.

Various statistical tests were performed using SPSS statistical analysis software (SPSS v20, IBM Corp.). All the risk factors for chronic subdural hematomas, preoperative hematoma thickness, and hematoma characteristics based on computed tomograph (CT) scan appearance was compared preoperatively and postoperatively in both the groups. In all circumstances a probability $(p)$ value of $<0.05$ was considered statistically significant.

\section{Results}

A total of 156 patients were included in the study, among which 88 underwent TC and 68 patients underwent BHD for evacuation of CSDH. All patients underwent two trephines or burr holes placed according at the maximum thickness of the hematoma. Majority of the patients were males in both groups, 77 out of 88 in trephine, and 57 out of 68 in burr-hole group.

\section{Recurrence of cSDH}

The rate of symptomatic recurrence of cSDH in our study was $12.17 \%$ ( 19 out of 156 ). These patients required a second surgery. We observed that nontraumatic $\mathrm{CSDH}$, anticoagulant use, presence of membranes, preoperative $\mathrm{CT}$ showing iso- or mixed-density subdural collection, and SDH volume $>60 \mathrm{~mL}$ were the significant factors associated with higher chance of recurrence (-Table 1). Other considered risk factors like chronic alcoholism, smoking, coronary artery disease, cerebrovascular accident, chronic kidney disease, chronic liver disease, cancer chemotherapy, recent cranial surgery, diabetes, hypertension, psychiatric disorder, and drug use were not associated with significant difference in risk of recurrence or outcome.

\section{Comparison of Trephine Craniotomy with Burr Hole Drainage}

The clinical features of both the groups were shown in - Table 2 and were comparable. Various characteristics of the two groups are shown in - Table 3. Average operation time was slightly greater in trephine group (48.66 minutes) than burr-hole group (36.58 minutes) but this was not statistically significant. Average hospital stay was also comparable in both groups (trephine-5.03 days vs. burr-hole-4.69 days).

Rate of recurrence in trephine group was $12.5 \%$ and in burr-hole group was $11.76 \%$. Both the groups were comparable, with no statistical difference in the baseline characteristics, except for presence of membranes in the preoperative CT scan. Patients with preoperative CT scan showing different density cSDH separated by membranes ( - Fig. 2) were significantly common in TC group than in $\mathrm{BH}$ group.
Table 1 Comparing various factors for recurrence of chronic subdural hematoma

\begin{tabular}{|c|c|c|c|}
\hline & $\begin{array}{l}\text { No } \\
\text { recurrence } \\
\text { (137) }\end{array}$ & $\begin{array}{l}\text { Recurrence } \\
\text { (19) }\end{array}$ & $p$-Value \\
\hline Gender & & & 0.353 \\
\hline Male & 119 & 15 & \\
\hline Female & 18 & 4 & \\
\hline Side & & & 0.561 \\
\hline Right & 45 & 5 & \\
\hline Left & 69 & 12 & \\
\hline Bilateral & 23 & 2 & \\
\hline Admission GCS & & & 0.848 \\
\hline$<8$ & 11 & 1 & \\
\hline $9-12$ & 22 & 3 & \\
\hline $13-14$ & 25 & 5 & \\
\hline 15 & 79 & 10 & \\
\hline \multicolumn{4}{|l|}{ Cause of SDH } \\
\hline Traumatic & 125 & 14 & 0.021 \\
\hline Nontraumatic & 12 & 5 & \\
\hline $\begin{array}{l}\text { Chronic } \\
\text { alcoholism }\end{array}$ & 32 & 2 & 0.201 \\
\hline Smoking & 20 & 3 & 0.891 \\
\hline $\begin{array}{l}\text { Anticoagulant } \\
\text { use }\end{array}$ & 11 & 5 & 0.014 \\
\hline CAD & 9 & 3 & 0.157 \\
\hline CVA & 7 & 0 & - \\
\hline CKD & 2 & 0 & - \\
\hline CLD & 1 & 0 & - \\
\hline $\begin{array}{l}\text { Recent brain } \\
\text { surgery }\end{array}$ & 1 & 0 & - \\
\hline $\begin{array}{l}\text { Cancer } \\
\text { chemotherapy }\end{array}$ & 1 & 1 & 0.099 \\
\hline Psychiatry drugs & 2 & 0 & - \\
\hline DM & 29 & 3 & 0.586 \\
\hline HTN & 43 & 8 & 0.351 \\
\hline SDH density & & & $<0.001$ \\
\hline Iso & 12 & 6 & \\
\hline Нуро & 118 & 5 & \\
\hline Mix & 7 & 8 & \\
\hline Average volume & & & $<0.001$ \\
\hline$<30 \mathrm{~mL}$ & 12 & 0 & \\
\hline $30-60 \mathrm{~mL}$ & 107 & 11 & \\
\hline$>60 \mathrm{~mL}$ & 18 & 8 & \\
\hline
\end{tabular}

(Continued) 
Table 1 (Continued)

\begin{tabular}{|c|c|c|c|}
\hline & $\begin{array}{l}\text { No } \\
\text { recurrence } \\
(137)\end{array}$ & $\begin{array}{l}\text { Recurrence } \\
\text { (19) }\end{array}$ & $p$-Value \\
\hline Midline shift & & & 0.113 \\
\hline$<5 \mathrm{~mm}$ & 42 & 4 & \\
\hline $5-10 \mathrm{~mm}$ & 72 & 8 & \\
\hline$>10 \mathrm{~mm}$ & 23 & 7 & \\
\hline Maximum thickness & & & 0.582 \\
\hline$<1 \mathrm{~cm}$ & 21 & 4 & \\
\hline $1-2 \mathrm{~cm}$ & 64 & 10 & \\
\hline$>2 \mathrm{~cm}$ & 52 & 5 & \\
\hline Intraop membrane & & & 0.010 \\
\hline Yes & 45 & 12 & \\
\hline No & 92 & 7 & \\
\hline Anesthesia & & & 0.886 \\
\hline GA & 13 & 2 & \\
\hline LA & 124 & 17 & \\
\hline GOS & & & 0.053 \\
\hline Favorable & 134 & 17 & \\
\hline Unfavorable & 3 & 2 & \\
\hline Mortality & 1 & 1 & 0.099 \\
\hline Memory deficits & & & 0.716 \\
\hline Yes & 71 & 9 & \\
\hline No & 66 & 10 & \\
\hline Altered sensorium & & & 0.870 \\
\hline Yes & 55 & 8 & \\
\hline No & 82 & 11 & \\
\hline Seizures & & & - \\
\hline Yes & 10 & 0 & \\
\hline No & 127 & 19 & \\
\hline Urinary incontinence & & & 0.358 \\
\hline Yes & 43 & 4 & \\
\hline No & 94 & 15 & \\
\hline Vomiting & & & 0.625 \\
\hline Yes & 36 & 6 & \\
\hline No & 101 & 13 & \\
\hline Speech symptoms & & & 0.524 \\
\hline Yes & 21 & 4 & \\
\hline No & 116 & 15 & \\
\hline Limb weakness & & & 0.394 \\
\hline Yes & 86 & 10 & \\
\hline No & 51 & 9 & \\
\hline
\end{tabular}

Abbreviations: CAD, coronary artery disease; CKD, chronic kidney disease; $\mathrm{CLD}$, chronic liver disease; DM, diabetes mellitus; HTN, hypertension; GA, general anesthesia; LA, local anesthesia; GCS, Glasgow Coma Scale; GOS, Glasgow Outcome Score; SDH, subdural hematoma.

Note: All significant values less than 0.05 are in bold.
As there was selection bias for the procedure, the rate of recurrence cannot be compared in the two groups. Presence of subdural membrane was clearly a risk factor for recurrence, and these patients were preferentially taken for TC; the percentage of subdural membrane found intraoperatively was significantly greater in trephine group (51.1\%) than burrhole group (17.6\%) ( $p$ value $<0.001$ ).

When all the patients who showed membranes in CT scan were excluded, there was no statistical difference in the base line characteristics of both the groups. After excluding the patients with membranes in preoperative CT scan, there was no significant difference in recurrence rate between the two groups (-Table 4).

\section{Comparison of Recurrence in Patients with Membranes in TC and BHD Groups}

In TC group with membranes, 8 out of 45 had recurrence, whereas in burr-hole group with membranes, 8 out of 12 had recurrence. This difference was statistically significant ( $p$ value $<0.001)$. Membranes seen in CT scan were demonstrated in all cases intraoperatively, in both TC $(-$ Fig. $\mathbf{3})$ and BHD (-Fig. 4).

\section{Surgical Outcome}

Glasgow outcome score was unfavorable for two patients in trephine group and three patients in burr-hole group; there was no mortality in trephine group and two mortalities in burr-hole group in which one was recurrent. The cause of death was ventilator associated pneumonia. Another patient did not improve after surgery and expired of ventilator dependence and multiorgan failure. In one patient of burr-hole craniotomy with recurrence, TC was done and in one patient of TC with recurrence and symptomatic pneumocephalus, subdural drain with underwater drainage was placed.

\section{Discussion}

Recurrence of chronic subdural hematoma is associated with higher mortality and morbidity. ${ }^{6,9-13}$ So, choosing appropriate surgical technique is of paramount importance.

A meta-analysis regarding surgical technique for $\mathrm{CSDH}$ supports primary twist drill craniostomy (TDC) drainage at the bedside for patients who are high-risk surgical candidates with nonseptated cSDH and craniotomy as a first-line evacuation technique for CSDH with significant membranes. ${ }^{9}$ We reserved TDC only for high risk patients and did not include it in our study.

Decision analysis study by Bradley et al recommended that even though craniotomy had fewer recurrences, it was associated with frequent and more serious complications than did BHD and hence suggested BHD as the most efficient choice for surgical drainage of uncomplicated cSDH.

They concluded that BHD balances a low recurrence rate with a low incidence of highly morbid complications. ${ }^{10}$

In another evidence-based review for $\mathrm{CSDH}$ comparing the three principal techniques-TDC, burr hole craniostomy, and craniotomy, it was concluded that TDC and burr hole 
Table 2 Showing no significant difference in the clinical features of both the groups

\begin{tabular}{|c|c|c|c|c|c|c|c|c|c|}
\hline & \multicolumn{4}{|c|}{ Trephine $(n=88)$} & \multicolumn{4}{|c|}{ Burr hole $(n=68)$} & \multirow[t]{2}{*}{$p$-Value } \\
\hline & $\begin{array}{l}\text { Total } \\
(88)\end{array}$ & $\begin{array}{l}\text { No recurrence } \\
\text { (77) }\end{array}$ & $\begin{array}{l}\text { Recurrence } \\
\text { (11) }\end{array}$ & $p$-Value & $\begin{array}{l}\text { Total } \\
(68)\end{array}$ & $\begin{array}{l}\text { No recurrence } \\
(60)\end{array}$ & $\begin{array}{l}\text { Recurrence } \\
\text { (8) }\end{array}$ & $p$-Value & \\
\hline Headache & & & & 0.255 & & & & 0.463 & 0.418 \\
\hline Yes & 50 & 42 & 8 & & 43 & 37 & 6 & & \\
\hline No & 38 & 35 & 3 & & 35 & 33 & 2 & & \\
\hline $\begin{array}{l}\text { Memory } \\
\text { deficits }\end{array}$ & & & & 0.639 & & & & 0.452 & 0.113 \\
\hline Yes & 76 & 67 & 9 & & 4 & 4 & 0 & & \\
\hline No & 12 & 10 & 2 & & 64 & 56 & 8 & & \\
\hline $\begin{array}{l}\text { Altered } \\
\text { sensorium }\end{array}$ & & & & 0.325 & & & & 0.365 & 0.879 \\
\hline Yes & 36 & 30 & 6 & & 27 & 25 & 2 & & \\
\hline No & 52 & 47 & 5 & & 41 & 35 & 6 & & \\
\hline Seizures & & & & 0.384 & & & & 0.396 & 0.673 \\
\hline Yes & 5 & 5 & 0 & & 5 & 5 & 0 & & \\
\hline No & 83 & 72 & 11 & & 63 & 55 & 8 & & \\
\hline $\begin{array}{l}\text { Urinary } \\
\text { incontinence }\end{array}$ & & & & 1.00 & & & & 0.175 & 0.377 \\
\hline Yes & 24 & 21 & 3 & & 23 & 22 & 1 & & \\
\hline No & 64 & 56 & 8 & & 45 & 38 & 7 & & \\
\hline Vomiting & & & & 0.281 & & & & 0.068 & 0.088 \\
\hline Yes & 19 & 18 & 1 & & 23 & 18 & 5 & & \\
\hline No & 69 & 59 & 10 & & 45 & 42 & 3 & & \\
\hline $\begin{array}{l}\text { Speech } \\
\text { symptoms }\end{array}$ & & & & 0.335 & & & & 0.851 & 0.693 \\
\hline Yes & 15 & 12 & 3 & & 10 & 9 & 1 & & \\
\hline No & 73 & 65 & 8 & & 58 & 51 & 7 & & \\
\hline $\begin{array}{l}\text { Limb } \\
\text { weakness }\end{array}$ & & & & 0.212 & & & & 0.892 & 0.779 \\
\hline Yes & 55 & 50 & 5 & & 41 & 36 & 5 & & \\
\hline No & 33 & 27 & 6 & & 27 & 24 & 3 & & \\
\hline
\end{tabular}

craniostomy can be considered first-tier treatment, while craniotomy may be used as second-tier treatment. ${ }^{3}$

A recent prospective analysis recommended bedside TDC as the least invasive surgical technique for treating cSDH without any visible septations on preoperative CT for patients in a poor general condition as a first therapy. ${ }^{11}$

In our study also, we observed that membranes in CT was a definitive risk factor for recurrence. In patients with membranes, there was significantly more recurrence when BHD was done. In the absence of membranes, when recurrence rates were compared, there was no statistical difference in rates of recurrence between TC and BHD.
Adam et al observed that recurrence requiring reoperation was significantly more in cases where large craniotomy with or without subdural drain placement than small trephine. ${ }^{14}$ They also observed that reoperation was found to be significantly more often with laminar type of CT scan and maximal thickness above $22 \mathrm{~mm} .{ }^{14}$ Even though previous studies suggest craniotomy in presence of membranes, ${ }^{3,9,11}$ large craniotomies are associated with higher risk of morbidity, blood loss, and prolonged anesthesia. As cSDH is a disease in the elderly, it is imperative that TC can be an alternative. The procedure does not need power drills, is easy to replace, has good cosmesis, requires shorter duration of surgery in comparison 
Table 3 Table comparing various parameters in both groups

\begin{tabular}{|c|c|c|c|c|c|c|c|c|c|}
\hline & \multicolumn{4}{|c|}{ Trephine $(n=88)$} & \multicolumn{4}{|c|}{ Burr hole $(n=68)$} & \multirow[t]{2}{*}{$p$-Value } \\
\hline & Total (88) & \begin{tabular}{|l|} 
No recurrence \\
$(77)$
\end{tabular} & $\begin{array}{l}\text { Recurrence } \\
(11)\end{array}$ & $p$-Value & Total (68) & \begin{tabular}{|l|} 
No recurrence \\
$(60)$
\end{tabular} & $\begin{array}{l}\text { Recurrence } \\
(8)\end{array}$ & $p$-Value & \\
\hline Gender & & & & 0.542 & & & & 0.764 & 0.513 \\
\hline Male & 77 & 68 & 9 & & 57 & 51 & 6 & & \\
\hline Female & 11 & 9 & 2 & & 11 & 9 & 2 & & \\
\hline Side & & & & 0.348 & & & & 0.661 & 0.061 \\
\hline Right & 23 & 20 & 3 & & 27 & 25 & 2 & & \\
\hline Left & 53 & 45 & 8 & & 28 & 24 & 4 & & \\
\hline Bilateral & 12 & 12 & 0 & & 13 & 11 & 2 & & \\
\hline Admission GCS & & & & 0.892 & & & & 0.809 & 0.817 \\
\hline$<8$ & 8 & 7 & 1 & & 4 & 4 & 0 & & \\
\hline $9-12$ & 13 & 11 & 2 & & 12 & 11 & 1 & & \\
\hline $13-14$ & 18 & 15 & 3 & & 12 & 10 & 2 & & \\
\hline 15 & 49 & 44 & 5 & & 40 & 35 & 5 & & \\
\hline Cause of SDH & & & & 0.076 & & & & 0.145 & 0.832 \\
\hline Traumatic & 78 & 70 & 8 & & 61 & 55 & 6 & & \\
\hline Nontraumatic & 10 & 7 & 3 & & 7 & 5 & 2 & & \\
\hline $\begin{array}{l}\text { Average duration of } \\
\text { symptoms (days) }\end{array}$ & 11.16 & & & & 6.12 & & & & \\
\hline $\begin{array}{l}\text { Average duration since } \\
\text { trauma (days) }\end{array}$ & 45.05 & & & & 49.55 & & & & \\
\hline Chronic alcoholism & 20 & 18 & 2 & 0.915 & 14 & 14 & 0 & 0.945 & 0.356 \\
\hline Smoking & 15 & 13 & 2 & 0.249 & 8 & 7 & 1 & 0.125 & 0.748 \\
\hline Anticoagulant use & 9 & 6 & 3 & 0.046 & 7 & 5 & 2 & 0.827 & 0.989 \\
\hline $\begin{array}{l}\text { Deranged } \\
\text { coagulation (without } \\
\text { anticoagulants) }\end{array}$ & 1 & 1 & 0 & & 0 & 0 & 0 & & \\
\hline CAD & 8 & 6 & 2 & 0.352 & 4 & 3 & 1 & 0.397 & 0.330 \\
\hline CVA & 3 & 3 & 0 & 0.505 & 4 & 4 & 0 & 0.452 & 0.459 \\
\hline CKD & 1 & 1 & 0 & 0.704 & 1 & 1 & 0 & 0.713 & 0.854 \\
\hline CLD & 0 & 0 & 0 & - & 1 & 1 & 0 & 0.713 & 0.254 \\
\hline Recent brain surgery & 0 & 0 & 0 & - & 1 & 1 & 0 & 0.713 & 0.254 \\
\hline Cancer chemotherapy & 0 & 0 & 0 & - & 2 & 1 & 1 & 0.600 & 0.105 \\
\hline Psychiatry drugs & 1 & 1 & 0 & 0.704 & 1 & 1 & 0 & 0.713 & 0.854 \\
\hline DM & 16 & 14 & 2 & 1.00 & 16 & 15 & 1 & 0.434 & 0.412 \\
\hline HTN & 28 & 23 & 5 & 0.299 & 23 & 20 & 3 & 0.740 & 0.943 \\
\hline SDH density & & & & 0.000 & & & & 0.000 & 0.312 \\
\hline
\end{tabular}

(Continued) 
Table 3 (Continued)

\begin{tabular}{|c|c|c|c|c|c|c|c|c|c|}
\hline Iso & 11 & 7 & 4 & & 7 & 5 & 2 & & \\
\hline Нуро & 69 & 66 & 3 & & 54 & 52 & 2 & & \\
\hline Mix & 8 & 4 & 4 & & 7 & 3 & 4 & & \\
\hline Average volume & & & & 0.045 & & & & 0.088 & 0.196 \\
\hline$<30 \mathrm{~mL}$ & 9 & 9 & 0 & & 3 & 3 & 0 & & \\
\hline $30-60 \mathrm{~mL}$ & 61 & 56 & 6 & & 56 & 51 & 5 & & \\
\hline$>60 \mathrm{~mL}$ & 17 & 12 & 5 & & 9 & 6 & 3 & & \\
\hline Midline shift & & & & 0.831 & & & & 0.035 & 0.888 \\
\hline$<5 \mathrm{~mm}$ & 25 & 22 & 3 & & 21 & 20 & 1 & & \\
\hline $5-10 \mathrm{~mm}$ & 45 & 40 & 5 & & 35 & 32 & 3 & & \\
\hline$>10 \mathrm{~mm}$ & 18 & 15 & 3 & & 12 & 8 & 4 & & \\
\hline Maximum thickness & & & & 0.471 & & & & 0.553 & 0.760 \\
\hline$<1 \mathrm{~cm}$ & 15 & 13 & 2 & & 10 & 8 & 2 & & \\
\hline $1-2 \mathrm{~cm}$ & 53 & 47 & 6 & & 41 & 37 & 4 & & \\
\hline$>2 \mathrm{~cm}$ & 40 & 37 & 3 & & 27 & 25 & 2 & & \\
\hline Intraop membrane & & & & 0.126 & & & & 0.011 & 0.000 \\
\hline Yes & $45(51.12 \%)$ & 37 (48.05\%) & 8 (72.72\%) & & $12(17.65 \%)$ & $8(13.33 \%)$ & $4(50 \%)$ & & \\
\hline No & $43(48.86 \%)$ & 40 (53.25\%) & $3(27.27 \%)$ & & 56 (82.35\%) & $52(86.66 \%)$ & $4(50 \%)$ & & \\
\hline GOS & & & & 0.105 & & & & 0.236 & 0.452 \\
\hline Favorable & 86 & 76 & 10 & & 65 & 58 & 7 & & \\
\hline Unfavorable & 2 & 1 & 1 & & 3 & 2 & 1 & & \\
\hline Mortality & 0 & 0 & 0 & - & 2 & 1 & 1 & 0.088 & 0.105 \\
\hline $\begin{array}{l}\text { Average hospital stay } \\
\text { (days) }\end{array}$ & 5.03 & 4.62 & 7.88 & & 4.69 & 4.12 & 8.95 & & \\
\hline
\end{tabular}

Abbreviations: Abbreviations: CAD, coronary artery disease; CKD, chronic kidney disease; CLD, chronic liver disease; DM, diabetes mellitus; HTN, hypertension; GA, general anesthesia; LA, local anesthesia; GCS, Glasgow Coma Scale; GOS, Glasgow Outcome Score; SDH, subdural hematoma.

with large craniotomies, can be done under LA, and there is no need of plates and screws for fixation also.

Various factors other than membranes have been implicated in the recurrence of cSDH. Rouzbeh et al reported that the strongest predictors of reoperation of CSDH were clopidogrel or warfarin use, hematoma loculation on preoperative $\mathrm{CT}$, and the amount of hematoma evacuation on the first postoperative CT. ${ }^{12}$

In another study, Benaissa et al detected antiplatelet usage and right side as risk factors among various comorbidities studied for recurrent $\mathrm{CSDH} .{ }^{13}$

Another factor to be considered after the surgical procedure is placement of subdural drain.

Nishant et al observed low recurrence rates with the use of drains, and radiological demonstration of brain expansion before drain removal. ${ }^{15}$
Amit Kumar et al also observed that use of a subdural drain after burr-hole evacuation of a cSDH reduces the recurrence rate and is not associated with increased complications. ${ }^{16}$

In a recent prospective randomized study by Soleman et al, ${ }^{17}$ the authors concluded that placement of a sub periosteal drain led to lower recurrence rates, fewer surgical infections, and lower drain misplacement rates than sub dural drains, and suggested that sub periosteal placement of drain routine clinical practice. ${ }^{17}$

But we did not use subdural drains in our study. We observed that nontraumatic cSDH, anticoagulant use, presence of membranes, preoperative $\mathrm{CT}$ showing iso- or mixed-density subdural collection, and SDH volume $>60 \mathrm{~mL}$ were the significant factors associated with higher chance of recurrence. 

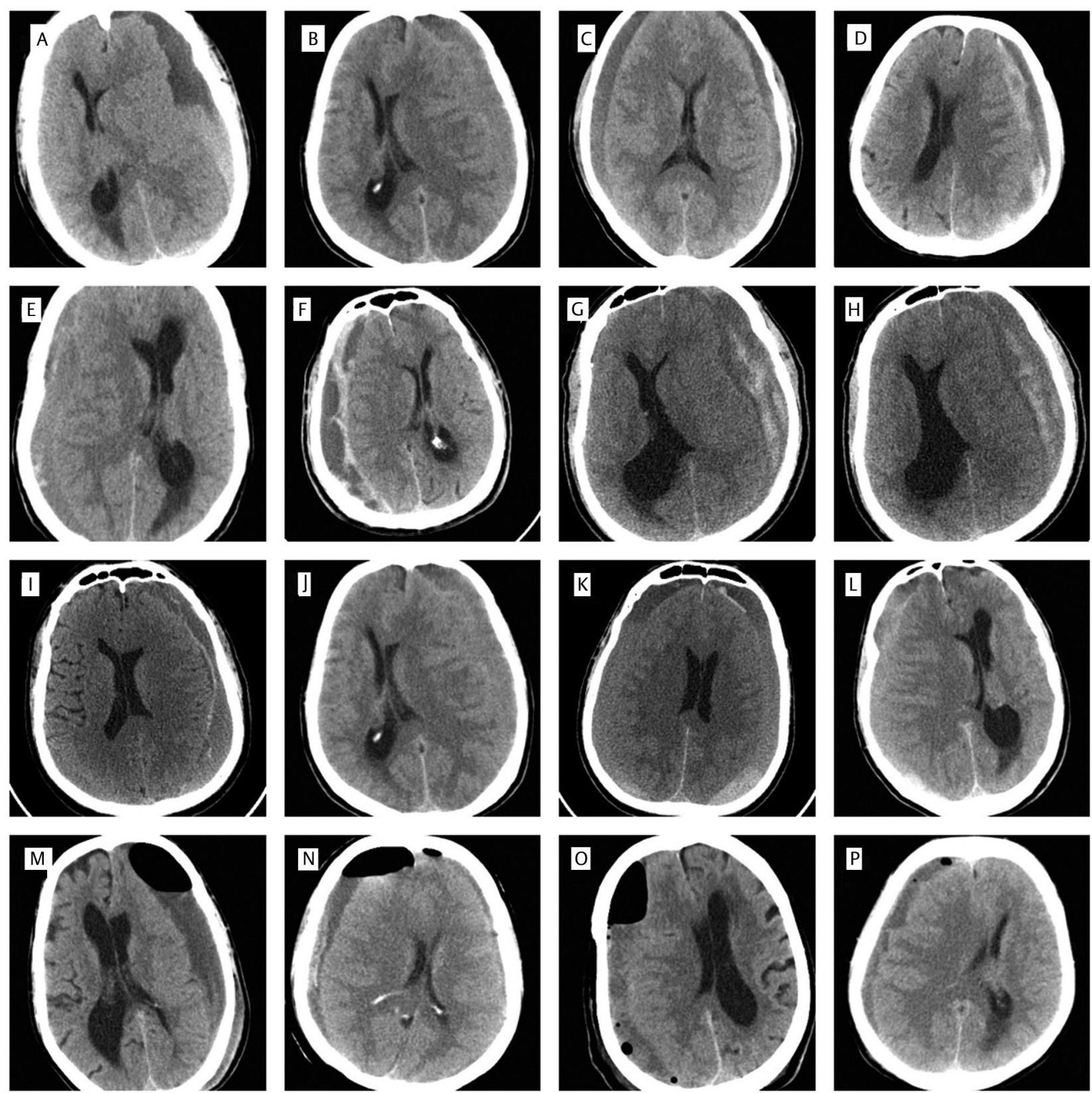

Fig. 2 Plain computed tomography (CT) of various patients with recurrence (A-L) showing different densities of subdural hematoma (SDH) hypo and iso with membranes $(\mathbf{A}-\mathbf{E})$ and loculated SDH $(\mathbf{F})$ isodense subdural collection (J-L). Postoperative CT of various patients with membranes showing recurrence (M-P). 

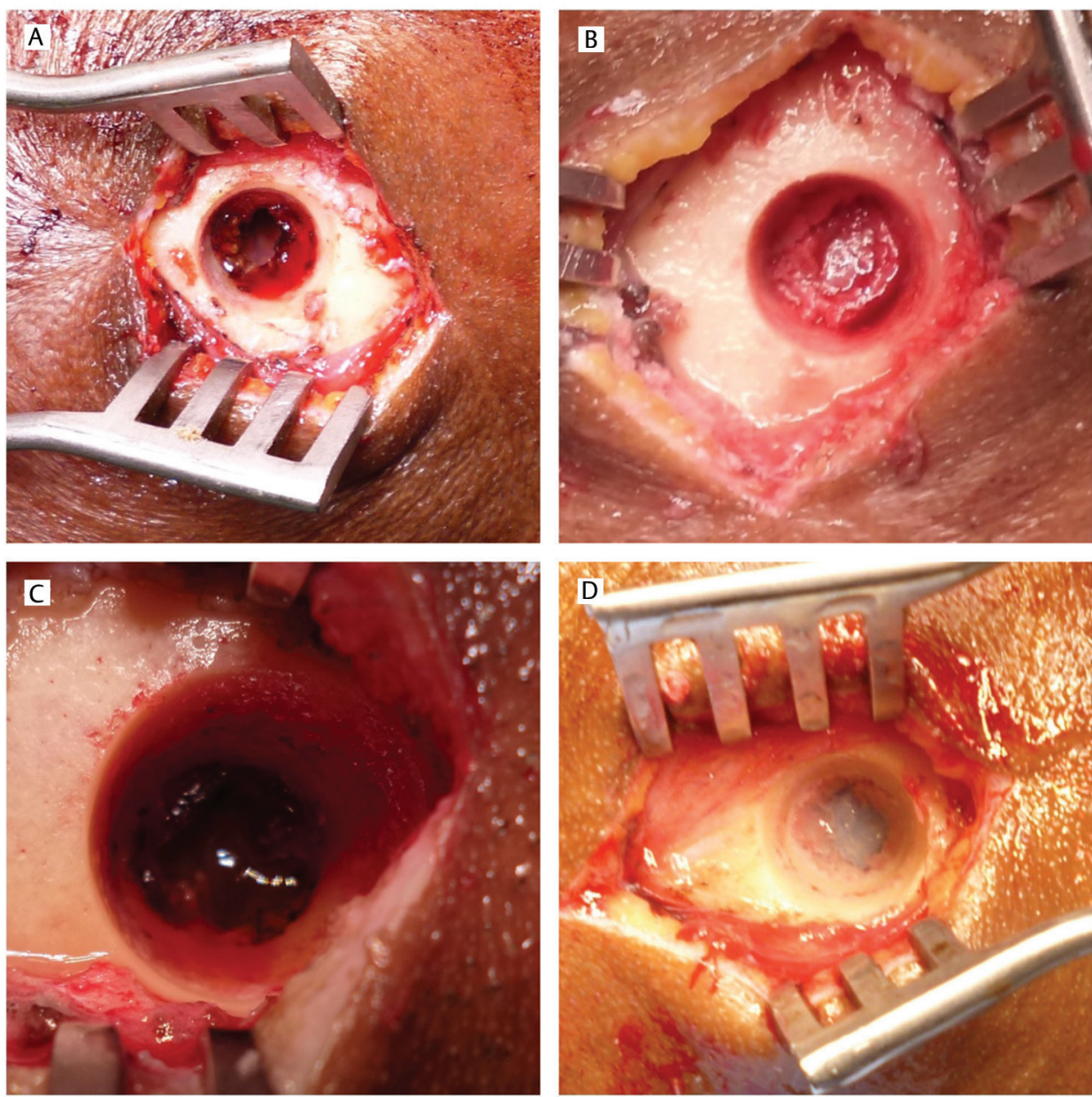

Fig. 3 Various cases (A, B, C, D) of burr hole drainage for subdural hematoma showing intraoperative membranes.

Table 4 Table showing no statistical difference in recurrence rates if patients with membranes were excluded from the study

\begin{tabular}{|l|l|l|l|}
\hline & $\begin{array}{l}\text { Recurrence } \\
\text { absent } \\
(n=90)\end{array}$ & $\begin{array}{l}\text { Recurrence } \\
\text { present } \\
(n=7)\end{array}$ & $\begin{array}{l}\text { Total } \\
(n=99)\end{array}$ \\
\hline $\begin{array}{l}\text { TC without } \\
\text { membranes }\end{array}$ & 40 & 3 & 43 \\
\hline $\begin{array}{l}\text { BHD without } \\
\text { membranes }\end{array}$ & 50 & 4 & 56 \\
\hline
\end{tabular}

Abbreviations: BHD, burr hole drainage; TC, trephine craniotomy; Note: $p$ value 0.975 .

Pragyan et al observed that young adults with CSDH show less severe clinical and radiologic features as well as fewer recurrences than noted in the elderly population and BHD is satisfactory in them. ${ }^{18}$
A variety of alternative techniques have also been suggested in the setting of recurrent hematoma formation. For example, several groups have reported on the efficacy of middle meningeal artery embolization in the treatment of refractory chronic subdural hematoma ${ }^{19-21}$ But we have no experience in this.

An additional adjunctive technique proposed in the treatment of recurrent cSDH is implantation of an ommaya reservoir, which permits repeated punctures and aspiration of subdural fluid. In an early prospective study by Laumer et al, ${ }^{22}$ they observed that the reoperation rate was fourfold greater in the groups treated with conventional therapy compared with the group treated with the ommaya implant system. A similar technique that has been employed for the treatment of recurrent CSDH is subduroperitoneal shunting. ${ }^{7,23,24}$ Although only reported in a small number of series, there have been no reported complications, and only a single recurrence was reported following placement. However, placement of a subduroperitoneal shunt requires GA, increased operative time, and carries the risk of increased shunt-related infection. 

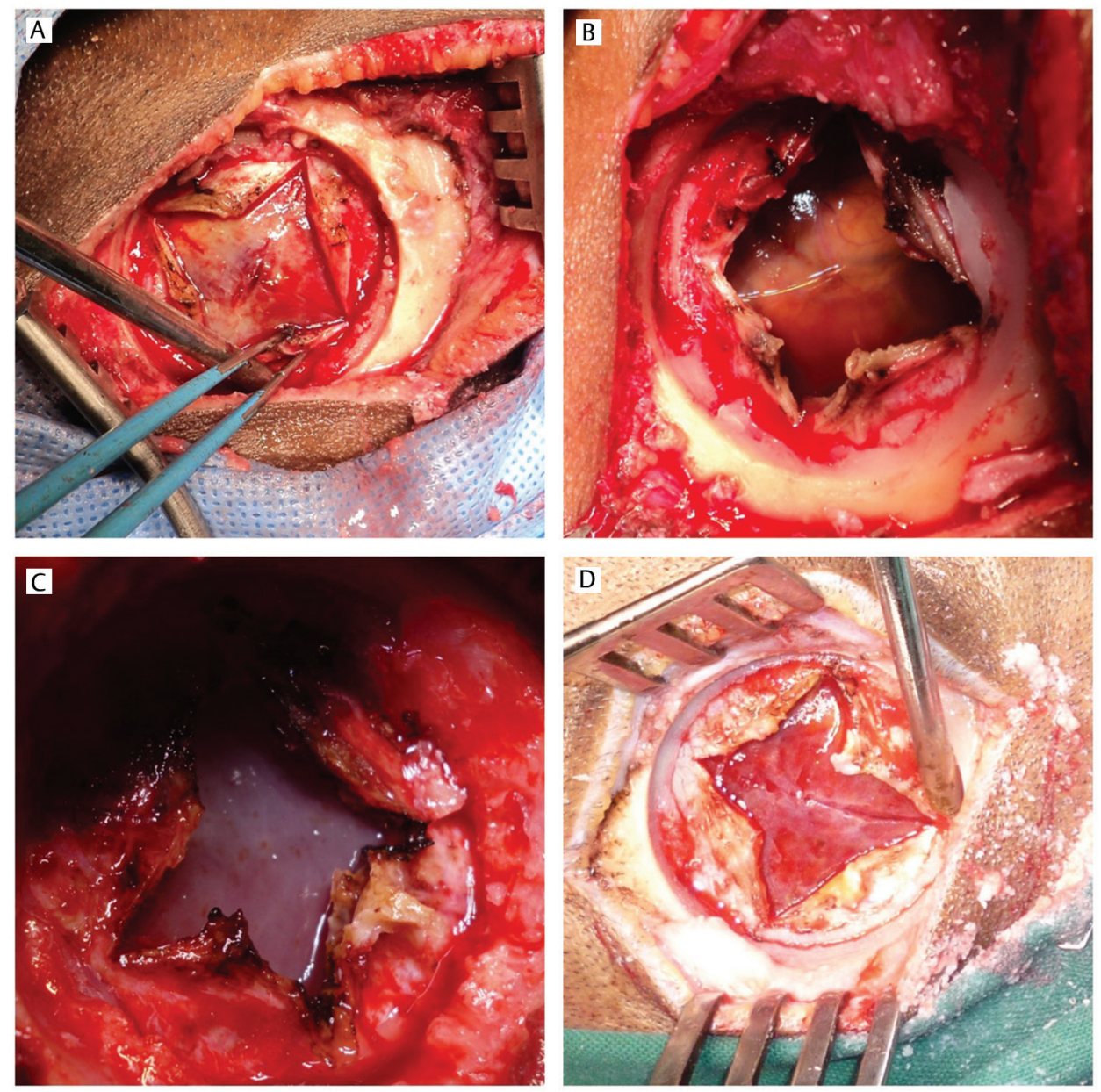

Fig. 4 Various cases (A, B, C, D) of trephine craniotomy for subdural hematoma showing intraoperative membranes.

\section{Conclusions}

Surgical intervention for symptomatic CSDH has a good outcome with an overall recurrence of $12.7 \%$. This recurrence rate falls down to $7 \%$ in patients without any membranes in preoperative CT scans. Presence of membranes in CT scan is a significant risk factor for recurrence. Recurrence rate in these patients with membranes is significantly lower with TC than BHD. Hence, for cSDH without any identifiable membranes in CT scan, BHD is the preferred mode of intervention as it balances the rate of recurrence and complications with effectiveness of management. For patients of CSDH with membranes identified in CT scan, we prefer TC as first line of management rather than doing a large craniotomy. Large prospective trials are needed to confirm these observations. This does not include patients of acute (hyperdense) component on CT scan.

\section{Conflict of Interest}

None declared.

\section{References}

1 Yang AI, Balser DS, Mikheev A, et al. Cerebral atrophy is associated with development of chronic subdural haematoma. Brain Inj 2012;26(13-14):1731-1736

2 Rauhala M, Luoto TM, Huhtala $\mathrm{H}$, et al. The incidence of chronic subdural hematomas from 1990 to 2015 in a defined Finnish population. J Neurosurg 2019;1-11 (e-pub ahead of print). doi: 10.3171/2018.12.JNS183035.

3 Weigel R, Schmiedek P, Krauss JK. Outcome of contemporary surgery for chronic subdural haematoma: evidence based review. J Neurol Neurosurg Psychiatry 2003;74(7):937-943

4 Markwalder TM, Seiler RW. Chronic subdural hematomas: to drain or not to drain.? Neurosurgery 1985;16(2):185-188

5 Gonugunta V, Buxton N. Warfarin and chronic subdural haematomas. Br J Neurosurg 2001;15(6):514-517

6 Markwalder TM. Chronic subdural hematomas: a review. J Neurosurg 1981;54(5):637-645

7 Probst C. Peritoneal drainage of chronic subdural hematomas in older patients. J Neurosurg 1988;68(6):908-911

8 Rodziewicz GS, Chuang WC. Endoscopic removal of organized chronic subdural hematoma. Surg Neurol 1995;43(6):569572, discussion 572-573 
9 Ducruet AF, Grobelny BT, Zacharia BE, et al. The surgical management of chronic subdural hematoma. Neurosurg Rev 2012;35(2):155-169, discussion 169

10 Lega BC, Danish SF, Malhotra NR, Sonnad SS, Stein SC. Choosing the best operation for chronic subdural hematoma: a decision analysis. J Neurosurg 2010;113(3):615-621

11 Reinges MH, Hasselberg I, Rohde V, Küker W, Gilsbach JM. Prospective analysis of bedside percutaneous subdural tapping for the treatment of chronic subdural haematoma in adults. J Neurol Neurosurg Psychiatry 2000;69(1):40-47

12 Motiei-Langroudi R, Stippler M, Shi S, et al. Factors predicting reoperation of chronic subdural hematoma following primary surgical evacuation. J Neurosurg 2018;129(5):1143-1150

13 Abdennebi B, Al Shamiri M. Recurrent chronic subdural hematoma: clinical and imaging risk factors. IJNT 2018;15(1):8-15

14 Adam D, Iftimie D, Moisescu C. Recurrence of chronic subdural hematomas requiring reoperation: could small trephination be a valid alternative to conventional approaches? Romanian Neurosurgery 2018;2:187-204

15 Yagnick NS, Moolchandani S, Sinha S, Mehta VS. Demonstration of brain expansion in cases of chronic SDH during admission leads to decreased rates of recurrence. IJNT 2019;16(1):63-66

16 Singh AK, Suryanarayanan B, Choudhary A, Prasad A, Singh S, Gupta LN. A prospective randomized study of use of drain versus no drain after burr-hole evacuation of chronic subdural hematoma. Neurol India 2014;62(2):169-174
17 Soleman J, Lutz K, Schaedelin S, et al. Subperiosteal vs subdural drain after burr-hole drainage of chronic subdural hematoma: a randomized clinical trial (cSDH-Drain-Trial) Neurosurgery 2019;85(5):E825-E834

18 Sarma P, Devi BI, Shukla DP, Bhat DI. Subacute and chronic subdural hematoma in young population less than 40 years. Indian J Neurotrauma 2014;11(1):1-4

19 Ishihara H, Ishihara S, Kohyama S, et al. Experience in endovascular treatment of recurrent chronic subdural hematoma. Interv Neuroradiol 2007;13(suppl 1) :141-144

20 Mandai S, Sakurai M, Matsumoto Y. Middle meningeal artery embolization for refractory chronic subdural hematoma. Case report. J Neurosurg 2000;93(4):686-688

21 Mino M, Nishimura S, Hori E, et al. Efficacy of middle meningeal artery embolization in the treatment of refractory chronic subdural hematoma. Surg Neurol Int 2010;1:78

22 Laumer R, Schramm J, Leykauf K. Implantation of a reservoir for recurrent subdural hematoma drainage. Neurosurgery 1989;25(6):991-996

23 Misra M, Salazar JL, Bloom DM. Subdural-peritoneal shunt: treatment for bilateral chronic subdural hematoma. Surg Neurol 1996;46(4):378-383

24 Santarius T, Qureshi HU, Sivakumaran R, Kirkpatrick PJ, Kirollos RW, Hutchinson PJ. The role of external drains and peritoneal conduits in the treatment of recurrent chronic subdural hematoma. World Neurosurg 2010;73(6):747-750 